\title{
Vibration Performance Comparison Study on Current Fiber Optic Connector Technologies
}

\author{
William J. Thomes, Jr. ${ }^{a}$, Frank V. LaRocca ${ }^{a}$, Robert C. Switzer ${ }^{a}$, Melanie N. Ott ${ }^{b}$, \\ Rick F. Chuska ${ }^{a}$, Shawn L. Macmurphy ${ }^{a}$ \\ ${ }^{a}$ MEI Technologies / NASA Goddard Space Flight Center, Lanham, MD, USA 20706 \\ 'NASA Goddard Space Flight Center, Greenbelt, MD, USA 20771
}

\begin{abstract}
Fiber optic cables are increasingly being used in harsh environments where they are subjected to vibration. Understanding the degradation in performance under these conditions is essential for integration of the fibers into the given application. System constraints oftentimes require fiber optic connectors so subsystems can be removed or assembled as needed. In the present work, various types of fiber optic connectors were monitored in-situ during vibration testing to examine the transient change in optical transmission and the steady-state variation following the event. Inspection of the fiber endfaces and connectors was performed at chosen intervals throughout the testing.
\end{abstract}

Keywords: Space flight, fiber optics, fiber, vibration, fiber connector, fiber termination

\section{INTRODUCTION}

Fiber optic systems are being used in an ever increasing number of systems due to their advantages of lighter weight, lower power, smaller size, immunity to electrical interference, and higher data rate capability. These are especially important considerations when building systems that must be deployed, whether it is launching the system into space or mobile enough to carry around in the field. But, there are challenges to overcome when considering replacing electrical systems with optical ones. There has been considerable work done in addressing most of these concerns and fiber optic based systems have been successfully used in many high consequence systems where reliability and functionality are crucial. Today, most of the hesitation on implementing fiber-based platforms stems from lack of knowledge about the proper design and use of fiber optics instead of inherent problems with the available technologies.

In this paper we investigated the performance of various fiber optic connectors over successively harsher vibration testing levels. Almost all larger systems will require that there be points at which the fiber optic cables will need to be connected and disconnected. Various groups build different parts of the overall project and these parts will have to be integrated together. Choosing the correct fiber connector will allow integration with acceptable loss in transmission and stable operation over mission environments. ${ }^{[1-3]}$ Vibration performance is just one consideration when choosing the correct fiber optic cable design, and other factors such as thermal, radiation, and mechanical constraints will need to be included. For the current study, we examined the performance of the AVIM, FC, SMA, MTP, and MIL-SPEC 38999 with 29504 termini.

\section{EXPERIMENTAL DESIGN}

\subsection{VIBRATION TESTING PROFILES}

Vibration testing was performed at increasing levels in three mutually perpendicular axes. Vibration testing duration was $3 \mathrm{~min} / \mathrm{axis}$ in each orientation. The vibration profiles chosen represent random vibration at 10.0, 14.1,20.0, and $34.6 \mathrm{G}_{\mathrm{rms}}$. The $10.0 \mathrm{G}_{\mathrm{rms}}$ level is based on the acceptance level test criteria for small box components as specified in the General Environmental Verification Standard (GEVS) for NASA Goddard Space Flight Center (GSFC). ${ }^{[4]}$ The GEVS random vibration requirements have a lower level workmanship test of $6.8 \mathrm{G}_{\mathrm{nns}}$ that is a minimum test for all parts used on GSFC space flight systems. Previous experience with vibration testing of fiber optic cables and adapters suggested that this lower level 
would not be sufficient to cause measureable degradation of any of the fiber optic connectors being studied, therefore, the $10.0 \mathrm{G}_{\mathrm{rms}}$ level was chosen as an initial test condition. GEVS testing requirements provide a general guideline for any part being used for a GSFC mission. The GEVS testing levels are modified based on specific mission designs and analysis, but are used as a reference point. The only modification to the standard for the current testing is increasing the test duration from $1 \mathrm{~min} / \mathrm{axis}$ to $3 \mathrm{~min} / \mathrm{axis}$. This change was made based on recent flight project requirements that dictated the longer test to simulate launch conditions for a satellite. Table lgives the vibration testing levels over the range of frequencies from 20 to $2000 \mathrm{~Hz}$. Figure 1 shows a graphical representation of the $10.0 \mathrm{G}_{\mathrm{rms}}$ testing profile.

Table 1: 10.0 Grms Vibration Profile

\begin{tabular}{|c|c|c|c|c|c|c|}
\hline FREQ(Hz) & ASD(G $\left.\mathbf{G}^{2} / \mathbf{H z}\right)$ & $\mathbf{d B}$ & $\mathbf{O C T}$ & $\mathbf{d B} / \mathbf{O C T}$ & AREA & Grms \\
\hline 20.00 & 0.0130 & ${ }^{*}$ & ${ }^{*}$ & ${ }^{*}$ & ${ }^{*}$ & ${ }^{*}$ \\
\hline 50.00 & 0.0800 & 7.89 & 1.32 & 5.97 & 1.25 & 1.12 \\
\hline 800.00 & 0.0800 & 0.00 & 4.00 & 0.00 & 61.25 & 7.83 \\
\hline 2000.00 & 0.0130 & -7.89 & 1.32 & -5.97 & 99.91 & 10.00 \\
\hline
\end{tabular}

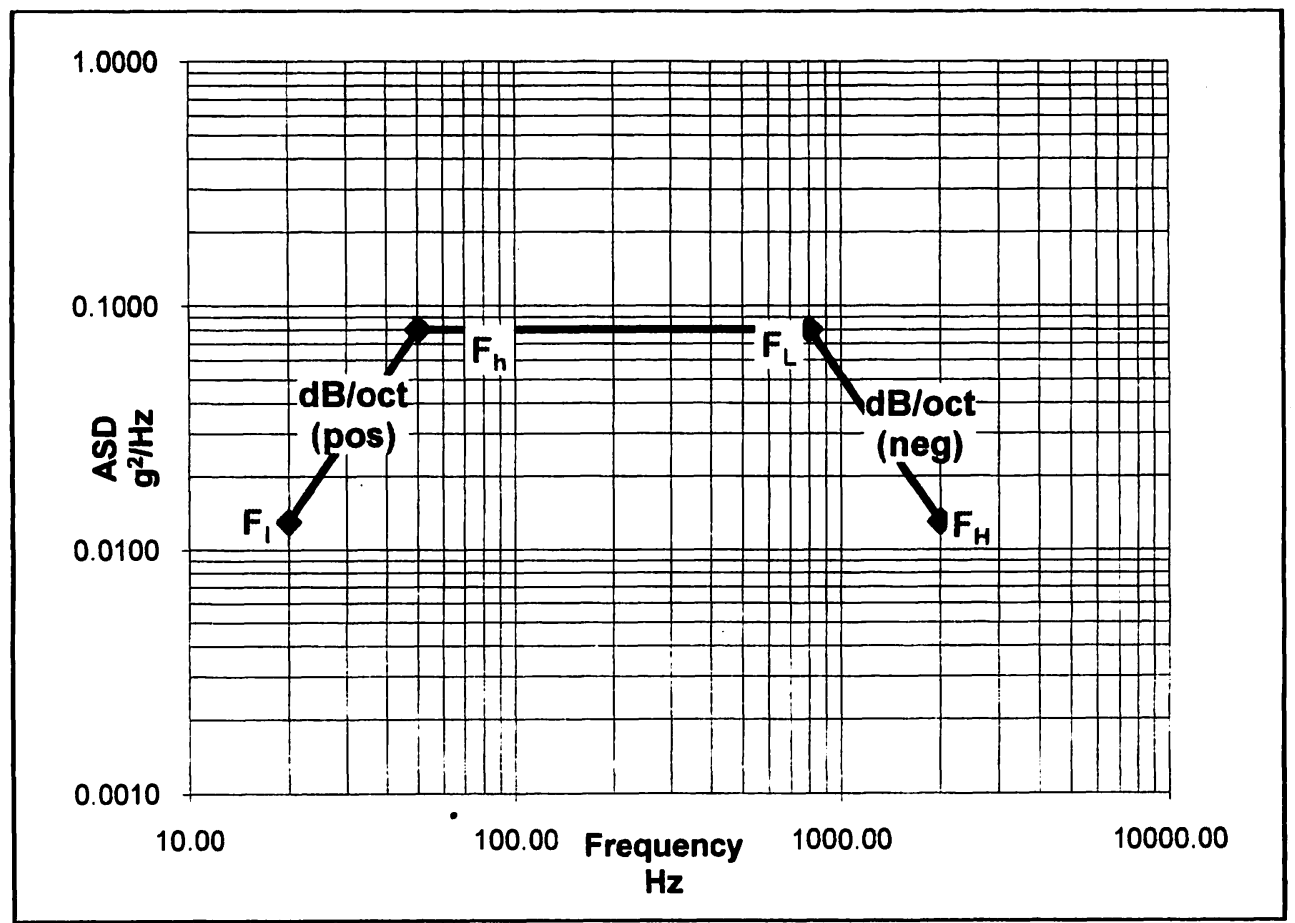

Figure 1: Vibration Profile for 10.0 Grms testing based on GEVS.

The next vibration level tested is $14.1 \mathrm{G}_{\mathrm{rms}}$ as derived from the GEVS requirements for random vibration qualification level testing of flight hardware. This would also be considered the protoflight level for components weighing $50 \mathrm{lb}$ or less. Table 2 gives the vibration testing levels over the range of frequencies from 20 to $2000 \mathrm{~Hz}$. Figure 2 shows a graphical representation of the $14.1 \mathrm{G}_{\mathrm{rms}}$ testing profile.

Table 2: 14.1 Grms Vibration Profile

\begin{tabular}{|c|c|c|c|c|c|}
\hline $\mathbf{A S D}\left(\mathbf{G}^{2} / \mathbf{H z}\right)$ & $\mathbf{d B}$ & $\mathbf{O C T}$ & $\mathbf{d B} / \mathbf{O C T}$ & AREA & Grms \\
\hline 0.0260 & ${ }^{\star}$ & ${ }^{\star}$ & ${ }^{\star}$ & ${ }^{\star}$ & ${ }^{\star}$ \\
\hline 0.1600 & 7.89 & 1.32 & 5.97 & 2.51 & 1.58 \\
\hline 0.1600 & 0.00 & 4.00 & 0.00 & 122.51 & 11.07 \\
\hline 0.0260 & -7.89 & 1.32 & -5.97 & 199.82 & 14.14 \\
\hline
\end{tabular}




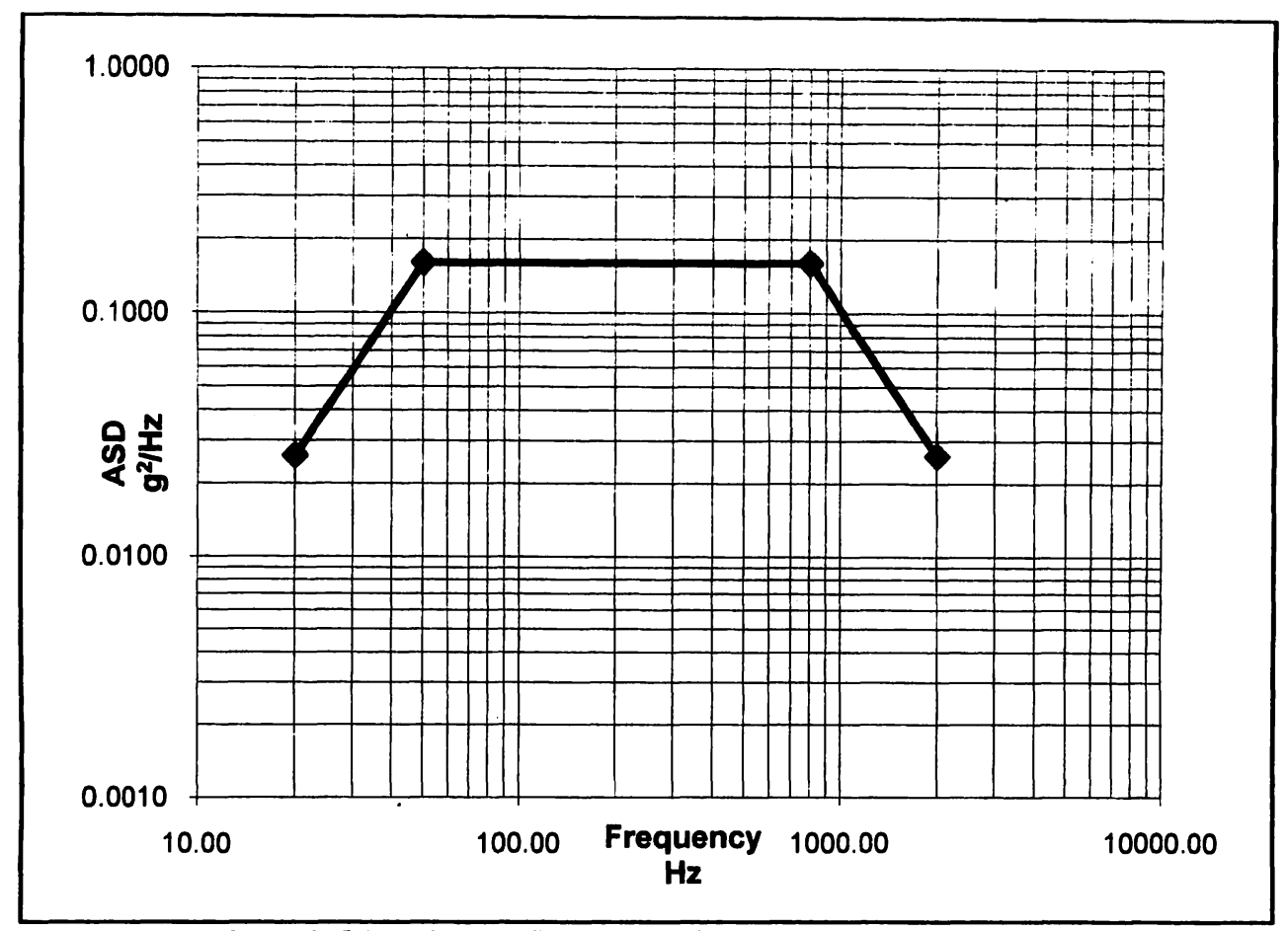

Figure 2: Vibration Profile for 14.1 Grms testing based on GEVS.

The NASA GSFC Code 562 Photonics Group has an internal standard for random vibration testing that has been derived from a compilation of requirements for various flight programs. We typically perform qualification level testing of fiber optic cables and custom assemblies to $20.0 \mathrm{G}_{\mathrm{rms}}$, which encompasses the vibration requirements across the frequencies of interest for the majority of flight programs. If properly designed, most assemblies will survive testing at this level without degradation of performance. Table 3 lists the vibration level and frequency for points at which a change occurs in the test profile. Figure 3 shows a graphical representation of the $20.0 \mathrm{G}_{\mathrm{rms}}$ profile.

Table 3: 20.0 Grms Vibration Profile

\begin{tabular}{|c|c|c|c|c|c|c|}
\hline FREQ(Hz) & ASD(G $\left.{ }^{2} / \mathbf{H z}\right)$ & $\mathbf{d B}$ & OCT & dB/OCT & AREA & Grms \\
\hline 20.00 & 0.0520 & $\star$ & ${ }^{*}$ & ${ }^{*}$ & ${ }^{*}$ & ${ }^{*}$ \\
\hline 50.00 & 0.3200 & 7.89 & 1.32 & 5.97 & 5.01 & 2.24 \\
\hline 800.00 & 0.3200 & 0.00 & 4.00 & 0.00 & 245.01 & 15.65 \\
\hline 2000.00 & 0.0520 & -7.89 & 1.32 & -5.97 & 399.63 & 19.99 \\
\hline
\end{tabular}




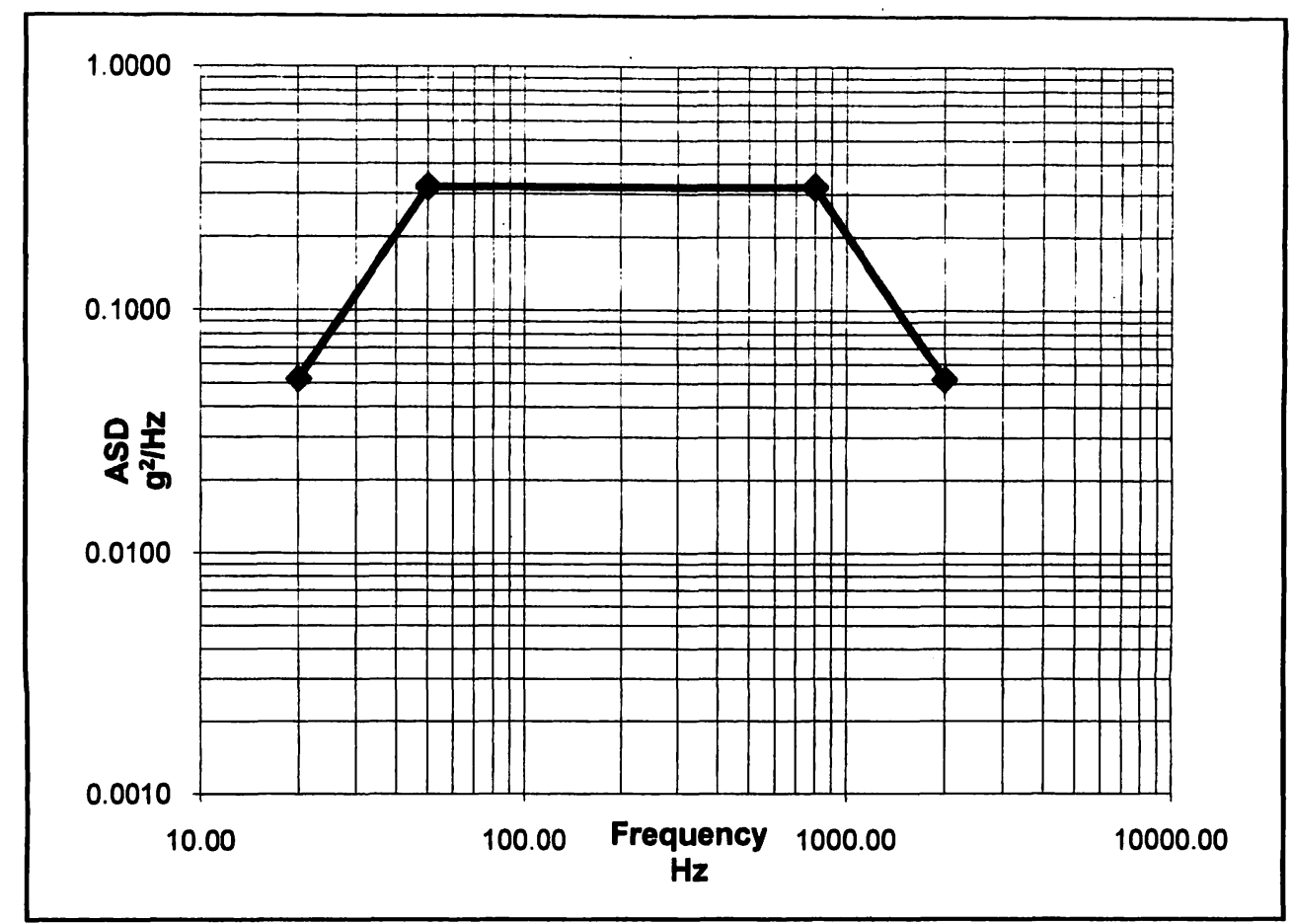

Figure 3: Vibration Profile for 20.0 Grms testing based on Photonics Group requirements.

Most space flight programs would not require testing to vibration levels higher than $20.0 \mathrm{G}_{\mathrm{rms}}$, but testing was also conducted to $34.6 \mathrm{G}_{\mathrm{ms}}$ in an attempt to expose weaknesses of any of the connectors in this study. The $34.6 \mathrm{G}_{\mathrm{rms}}$ level was chosen because of mechanical limitations of the vibration system being used. Vibration testing at higher levels would result in the shaker drum traveling outside of its displacement limits. Table 4 list the vibration profile and Figure 4 shows a graphical representation for the $34.6 \mathrm{G}_{\mathrm{ms}}$ testing.

Table 4: 34.6 Grms Vibration Profile

\begin{tabular}{|c|c|c|c|c|c|c|}
\hline FREQ(Hz) & $A S D\left(G^{2} / H z\right)$ & dB & OCT & $\mathrm{dB} / O C T$ & AREA & Grms \\
\hline 20.00 & 0.1560 & * & * & * & * & * \\
\hline 50.00 & 0.9600 & 7.89 & 1.32 & 5.97 & 15.04 & 3.88 \\
\hline 800.00 & 0.9600 & 0.00 & 4.00 & 0.00 & 735.04 & 27.11 \\
\hline 2000.00 & 0.1560 & -7.89 & 1.32 & -5.97 & 1198.89 & 34.63 \\
\hline
\end{tabular}




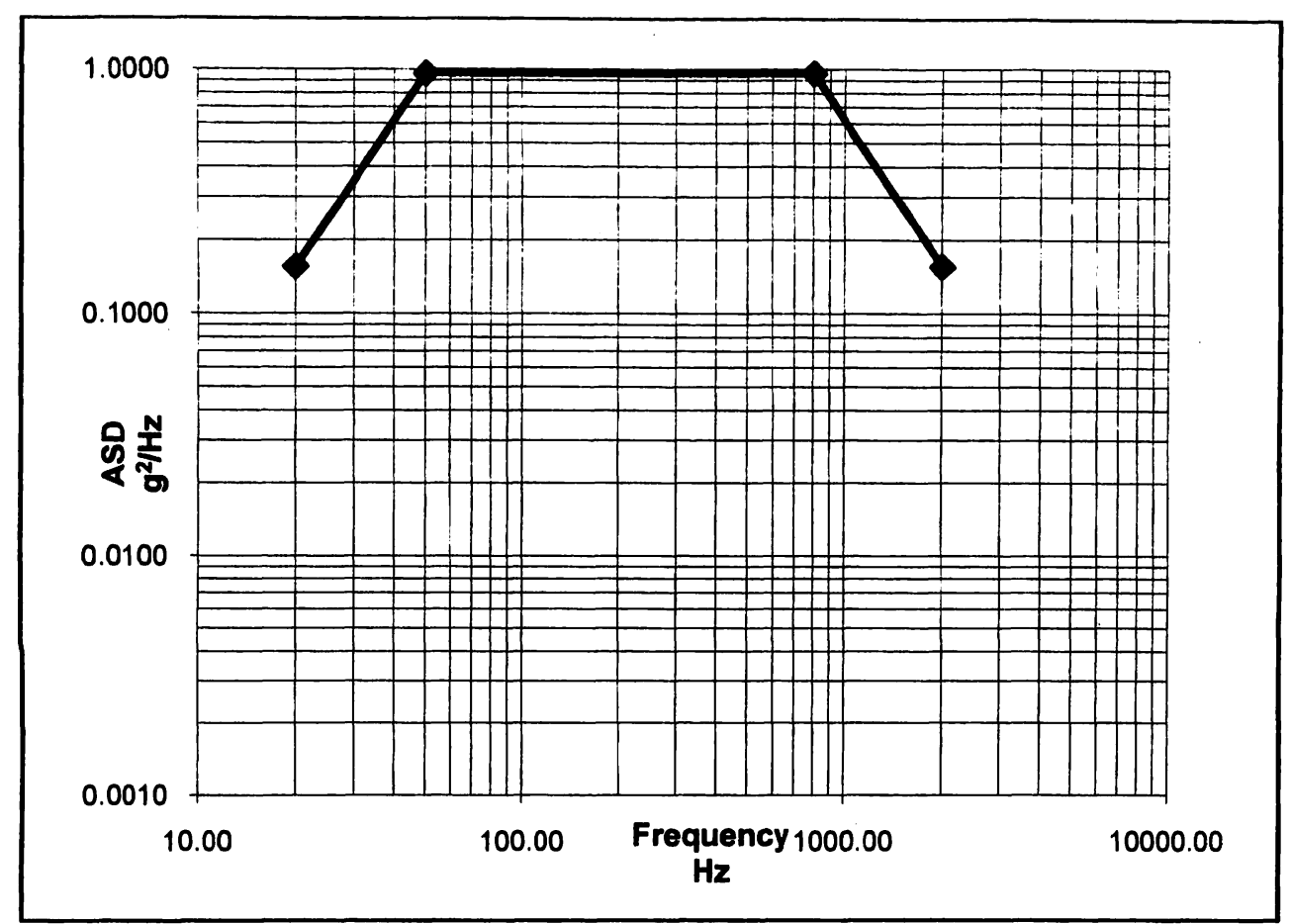

Figure 4: Vibration Profile for 34.6 Grms testing based on equipment limitations.

\subsection{Vibration Test Setup}

Vibration testing was conducted using a single axis vibration drum model $\mathrm{BW}-100 \mathrm{C} 2$ from $\mathrm{B}+\mathrm{W}$ Engineering with a BW-PA-4000 amplifier and DVC-4 controller. The fixture on the vibration drum allowed the fiber adapter to be mounted in various orientations to test the connectors in three mutually perpendicular axes. The first test at each vibration level was in the z-axis along the length of the connector body and ferrule. The second test was performed in the $\mathrm{x}$-axis parallel to the fiber ferrule endface with the connector key in the direction of travel. The third test was with the keyway rotated 90 degrees such that the vibration displacement was perpendicular to the connector key. For the connectors with no keying feature, a single test was done that combined the $\mathrm{x}$ and $\mathrm{y}$ axis because of symmetry around the connector and adapter.

Optical illumination was provided by a Rifocus 752L Dual LED source at either $850 \mathrm{~nm}$ or $1310 \mathrm{~nm}$. Light was split into two even channels using a $1 \times 2$ splitter. One channel of the splitter was connected to a detector to monitor the source during the test. The other channel was connected to a patch cable. The patch cables carried the light to and from the samples connected to the vibration drum. Specific patch cables were made for each type of connector being tested. The patch cables matched the fiber size and connector. The patch cable leading to the sample was also mandrel wrapped to ensure uniform illumination of the fibers under test. The return signal was captured using a HP (Agilent) $81532 \mathrm{~A}$ InGaAs detector. Data were captured using a custom LabView program running on a serial connection between the detectors and computer.

Testing was performed with the fiber optic cables in a mated pair configuration. Standard fiber adapters for the type of connector under test were used such that two endfaces were being tested during each experiment. Fiber pairs were kept the same throughout testing, so one damaged cable connector could not damage multiple other connectors.

Connectors were marked before each test and examined following the test to check for loosening. The connector was also checked by hand following the test to feel for any loosening. In addition, pictures were taken before and after each test to look for changes. 
An accelerometer was used as feedback to the vibration control system. The accelerometer also allowed monitoring of the vibration levels over the frequency range of interest being applied to the parts. A threaded mounting hole was located on various points of the fixture such that the accelerometer was in close proximity to the connection being tested.

\subsection{Fiber Terminations}

Three types of fiber cables were studied with the various connectors. These included a 100/140 step index fused silica fiber with a flat polish, a 400/440 step index fused silica fiber with a flat polish, and a 100/140 graded index fused silica fiber with a PC polish. The graded index fibers are usually used for communications applications at 1310 or $1550 \mathrm{~nm}$ and would have a PC polish. The PC polish leaves a slight curvature to the fiber endface such that the glass fiber cores are in intimate contact. This type of polish provides lower loss between the fibers, but places higher stresses on the fibers themselves. The germanium doped fiber is more brittle than the step index fused silica, so the combination of the PC polish and the graded index is expected to be the most susceptible to damage during testing. The step index fibers are usually used in sensing applications, which usually require a flat polish to avoid distortion of the optical signal. Figure 5 shows a representation of flat versus a PC polish.
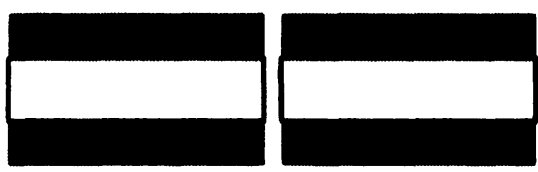

Flat Polish

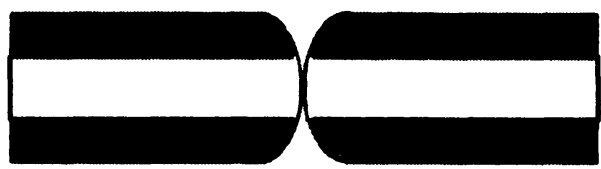

PC Polish

Figure 5: Representation of flat and PC polish of fiber endfaces.

Fiber endface pictures and interferometry were collected on each fiber before testing and after each vibration exposure. In this manner, a detailed picture and mapping of the fiber was performed at every given vibration level and orientation of the connector. Comparison of the data allows determination of exactly what vibration profile and axis the first signs of damage were observed.

\section{VIBRATION PERFORMANCE}

\subsection{The Diamond AVIM Connector}

The AVIM connector manufactured by Diamond is the baseline connector for many NASA GSFC missions. It has a $2.5 \mathrm{~mm}$ diameter ferrule that is either ceramic with a metal insert or all metal. The connector has a key inside for alignment with the adapter. The outer nut, which screws onto the adapter, has a ratcheting mechanism that prevents the nut from loosening during harsh environments. Since the ratcheting feature acts as a lock once installed, no secondary locking mechanism is needed. Figure 6 shows the AVIM connector and part of a low-profile adapter.
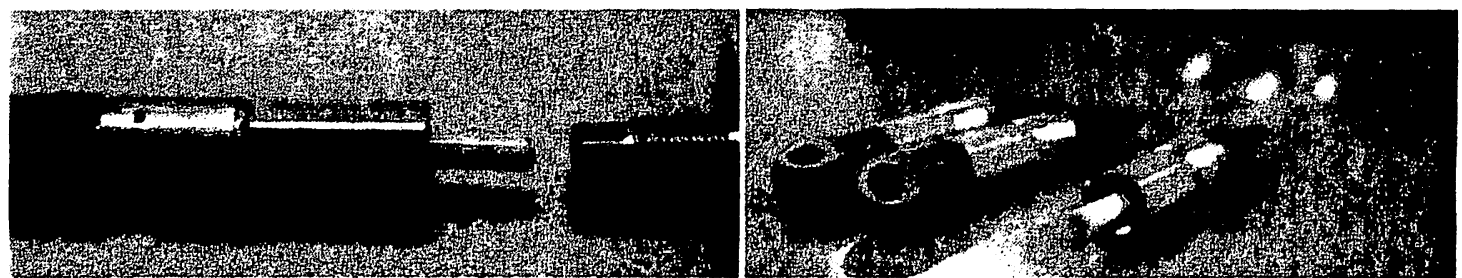

Figure 6: Diamond AVIM connector (ratcheting mechanism on nut slightly offset to show detail).

To obtain baseline vibration performance data for comparison with the other connector types, all three fiber types were tested with the AVIM connector. A standard low-profile AVIM adapter was used. The adapter has a split ceramic sleeve captured inside that provides the alignment between the fiber endfaces. Figure 7 through Figure 9 show representative insertion loss data during vibration testing of the different fibers in 
each axis. As can be seen from the graphs, the insertion loss change was less than $0.02 \mathrm{~dB}$. Figure 8 illustrates a small shift in the fiber alignment immediately after the start of the vibration testing, but optical performance is stable following this slight change.

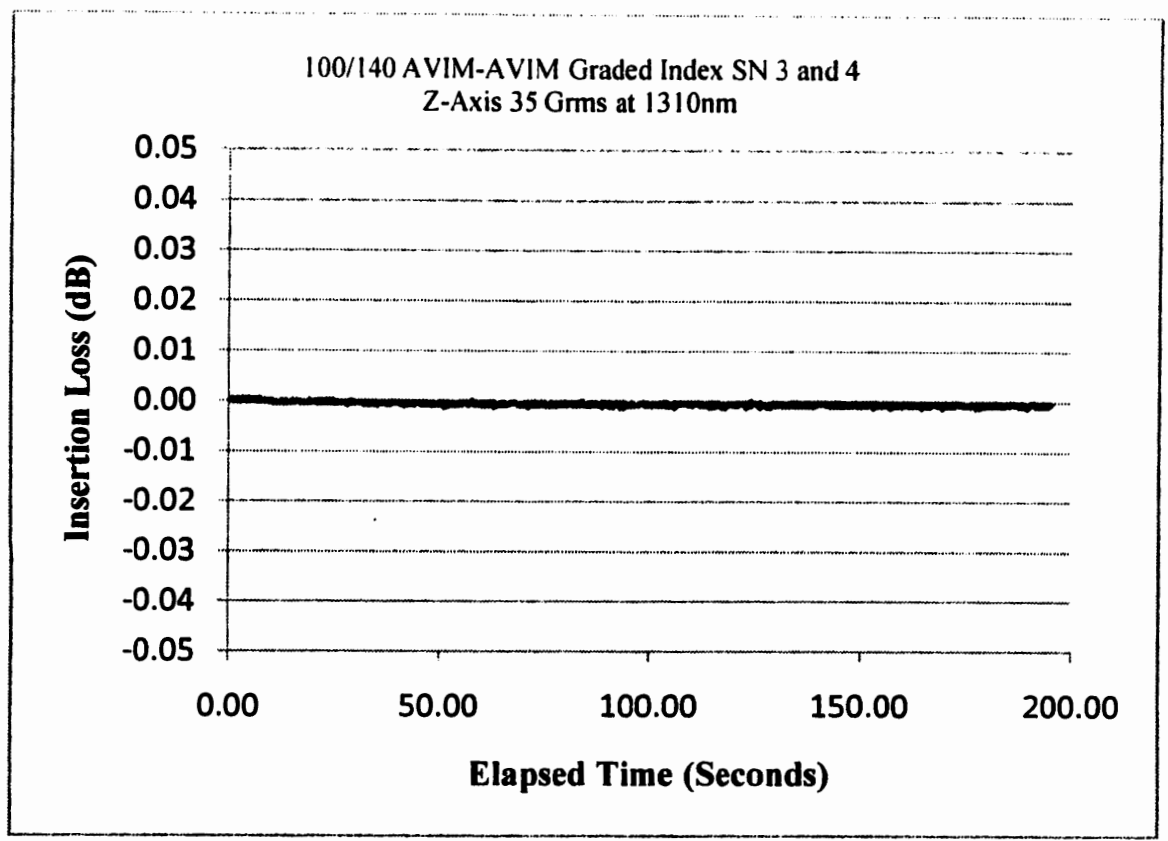

Figure 7: Insertion loss of $100 / 140$ graded index fiber in AVIM connector tested at 35 Grms along connector axis ( $Z$ axis).

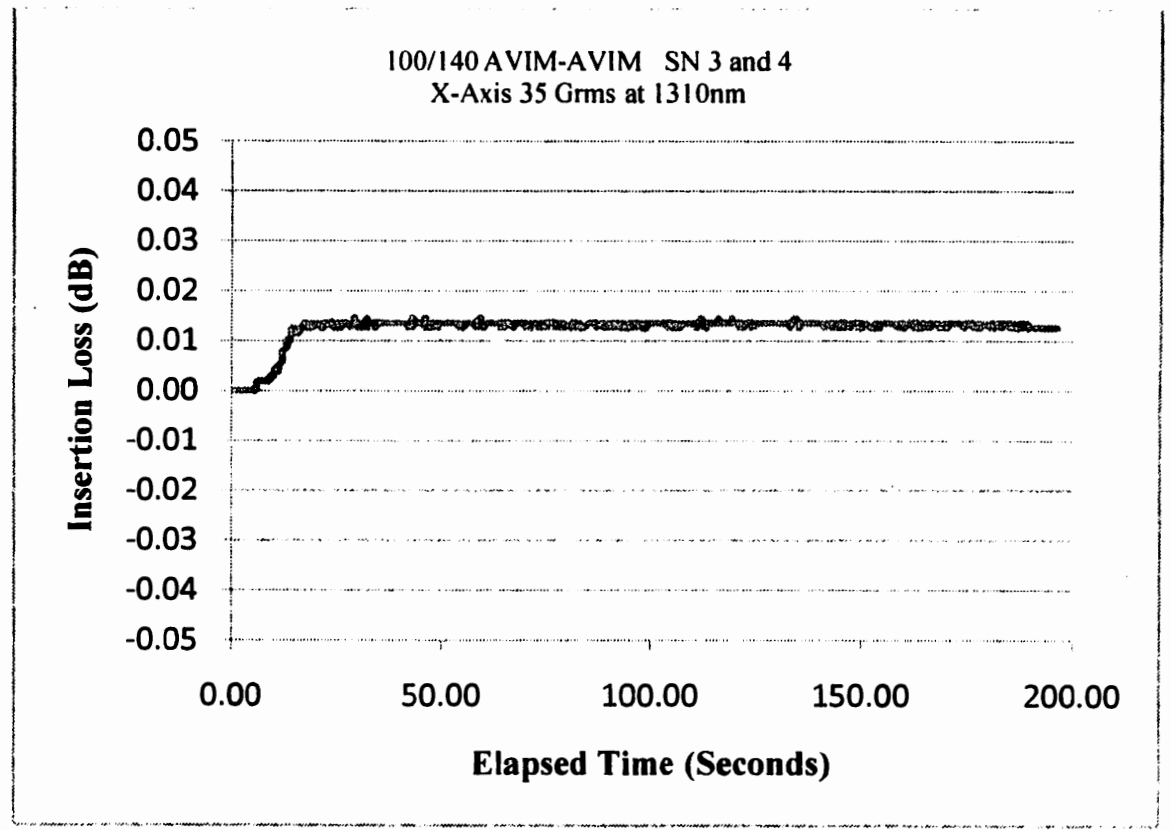

Figure 8: Insertion loss of $\mathbf{1 0 0 / 1 4 0}$ step index fiber in A VIM connector tested at 35 Grms perpendicular to ferrule endface with key in displacement direction ( $X$ axis). 


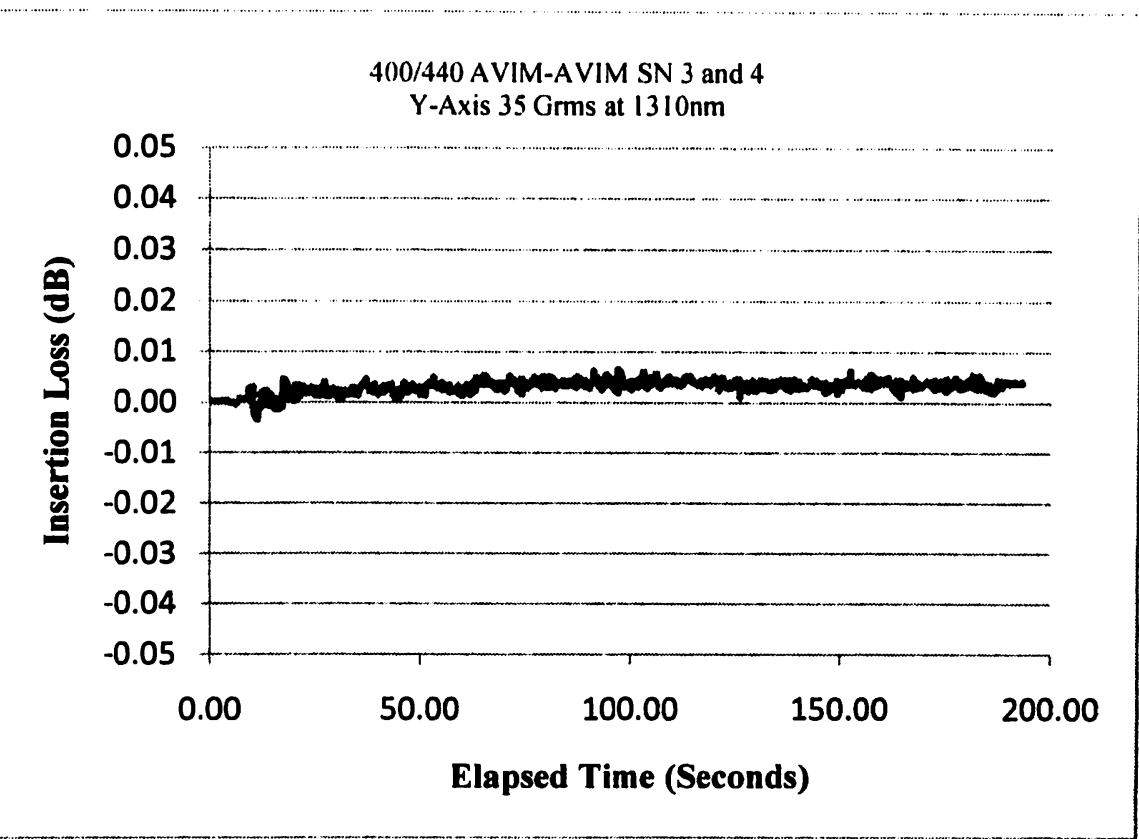

Figure 9: Insertion loss of $\mathbf{4 0 0 / 4 4 0 ~ s t e p ~ i n d e x ~ f i b e r ~ i n ~ A V I M ~ c o n n e c t o r ~ t e s t e d ~ a t ~} 35$ Grms perpendicular to ferrule endface with key perpendicular to displacement direction ( $Y$ axis).

No fiber endface damage was found following the vibration testing, but slight damage to the outer regions of the metal ferrules was seen. Figure 10 shows endface pictures of the fiber and ferrule for a $100 / 140$ graded index fiber (the most brittle tested) with a PC polish (resulting in highest forces on fibers). Most AVIM connectors tested exhibited similar issues. It appears that the adapters may have allowed the ferrules to pivot slightly about the center and make intermittent contact toward the edges of the ferrule. Thus the centers would not be losing contact with each other and avoiding damage to the glass fiber. Our group has noticed small metal contamination in the past from mating and de-mating of the metal connectors. While not specifically seen during this study, it is possible that small contamination pieces could contribute to this type of behavior.
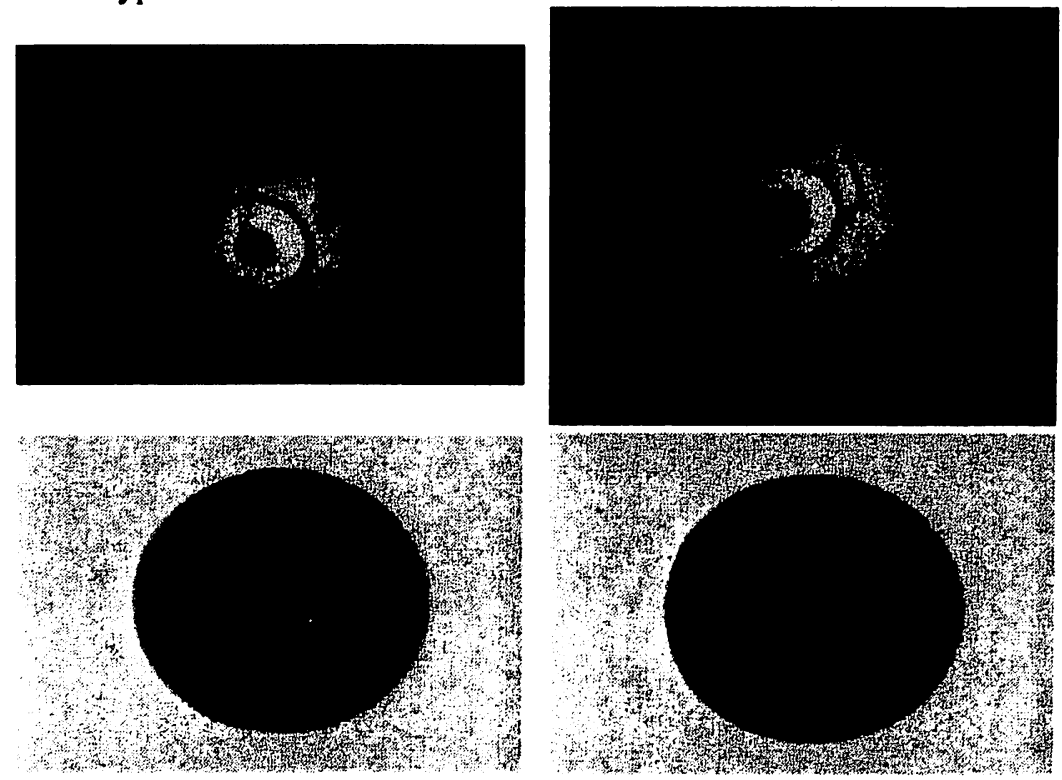

$$
\text { After } 10.0 \mathrm{G}_{\mathrm{rms}} \text { Testing }
$$$$
\text { After } 34.6 \mathrm{G}_{\mathrm{rms}} \text { Testing }
$$

Figure 10: Endface pictures of 100/140 graded index fiber with PC polish following vibration testing. 
Table 5: Insertion Loss of AVIM cables before and after vibration testing.

\begin{tabular}{|l|c|c|c|}
\hline \multicolumn{1}{|c|}{ Cable Identification } & $\begin{array}{c}\text { Insertion Loss } \\
\text { Pre-Vibration } \\
\text { Testing }\end{array}$ & $\begin{array}{c}\text { Insertion Loss } \\
\text { Post-Vibration Testing }\end{array}$ & $\begin{array}{c}\text { Insertion Loss } \\
\text { Change (dB) }\end{array}$ \\
\hline AVIM-AVIM 100/140 Step Index SN - & 0.27 & 0.53 & 0.26 \\
\hline AVIM-AVIM 100/140 Step Index SN - 2 & 0.02 & 0.21 & 0.18 \\
\hline AVIM-AVIM 100/140 Step Index SN - 3 & 0.14 & 0.09 & -0.05 \\
\hline AVIM-AVIM 100/140 Step Index SN - 4 & 0.12 & 0.17 & 0.04 \\
\hline AVIM-AVIM 100/140 Graded Index SN-1 & 0.01 & 0.14 & 0.14 \\
\hline AVIM-AVIM 100/140 Graded Index SN-2 & 0.01 & 0.25 & 0.24 \\
\hline AVIM-AVIM 100/140 Graded Index SN-3 & 0.21 & 0.14 & -0.07 \\
\hline AVIM-AVIM 100/140 Graded Index SN-4 & 0.01 & 0.16 & 0.15 \\
\hline AVIM-AVIM 400/440 SN-1 & 0.72 & 0.68 & -0.04 \\
\hline AVIM-AVIM 400/440 SN-2 & 0.72 & 0.63 & -0.09 \\
\hline AVIM-AVIM 400/440 SN-3 & 0.64 & 0.59 & -0.05 \\
\hline AVIM-AVIM 400/440 SN-4 & 0.69 & 0.62 & -0.07 \\
\hline
\end{tabular}

Table 5 gives the insertion loss of the AVIM cables before and after vibration testing. The maximum change in insertion loss following all vibration testing on these cables was $0.26 \mathrm{~dB}$. Due to the small magnitude of these changes and variability in the test setup, the cables are considered to have shown no degradation in performance due to the vibration testing.

\subsection{The FC Connector}

The FC connector has a ferrule nearly identical to the AVIM connector as shown in Figure 11. The springloaded ferrule is $2.5 \mathrm{~mm}$ in diameter. A connector key and matching slot on the adapter provide alignment and anti-rotation features. The connector attaches to the adapter with a larger outer nut. Secondary fastening is required for rugged environments to ensure the connector does not loosen.

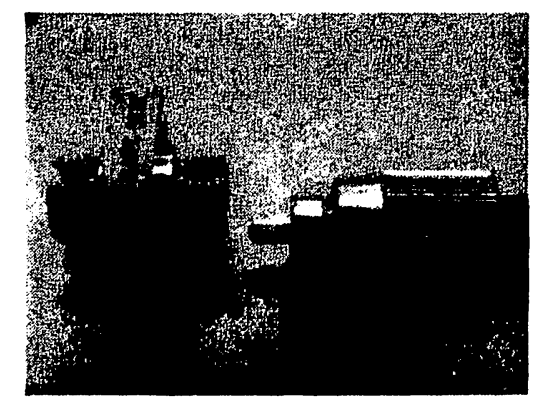

Figure 11: The FC connector and adapter.

Since the FC connector is similar to the AVIM in terms of the loads placed on the fiber ferrule, only the $400 / 440$ fiber was tested as part of this study to ensure similarity of optical performance and monitor for mechanical changes, such as loosening of the connector fastening nut. The adapter uses an identical split ceramic sleeve as to the AVIM to maintain alignment between the mated ferrules.

Insertion loss data from a representative vibration test of the FC connectors is given in Figure 12. Endface images are shown in Figure 13. Both results are similar to those found during evaluation of the AVIM connector, in which the insertion loss was essentially unchanged during vibration testing to $34.6 \mathrm{G}_{\text {rns, }}$, but the outer edges of the metal ferrule exhibited some pitting and scratching. 


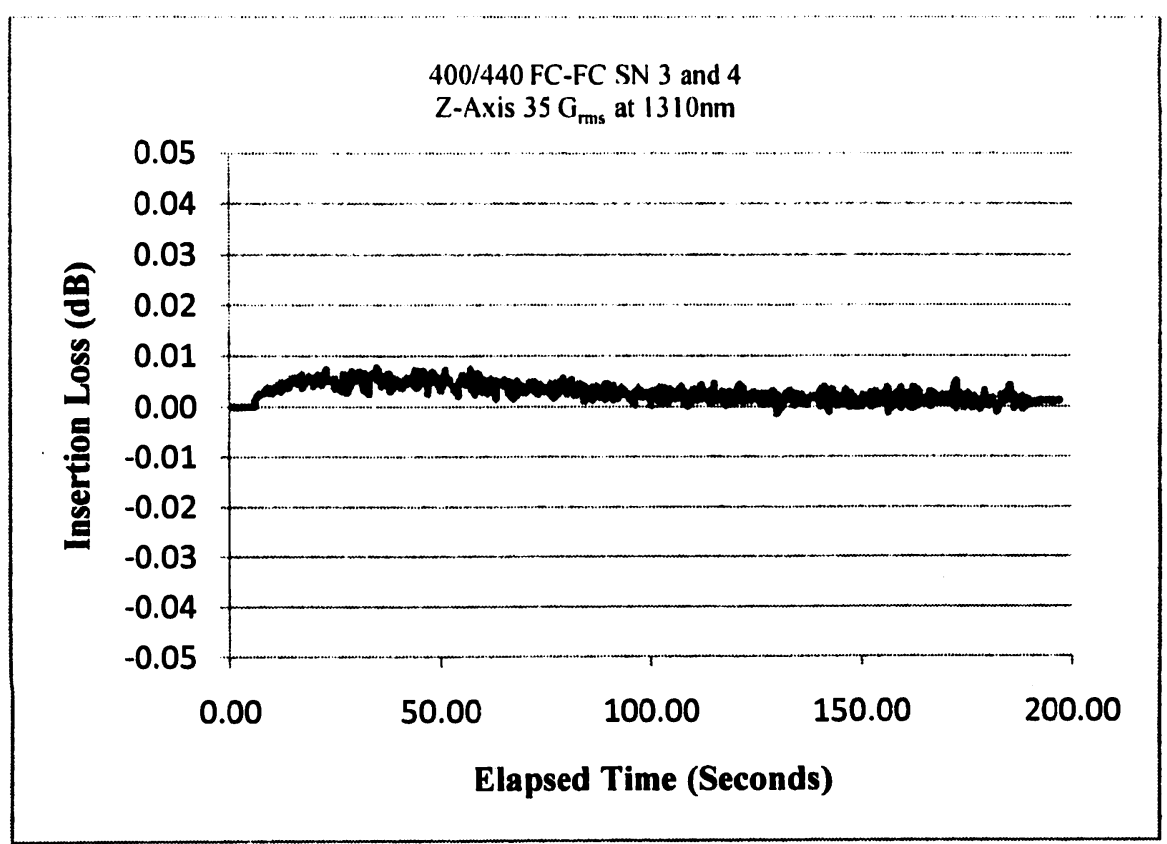

Figure 12: Insertion loss of $\mathbf{4 0 0 / 4 4 0 ~ s t e p ~ i n d e x ~ f i b e r ~ i n ~ a ~ F C ~ c o n n e c t o r ~ t e s t e d ~ a t ~} 35$ Grms along the connector axis ( $Z$ axis).
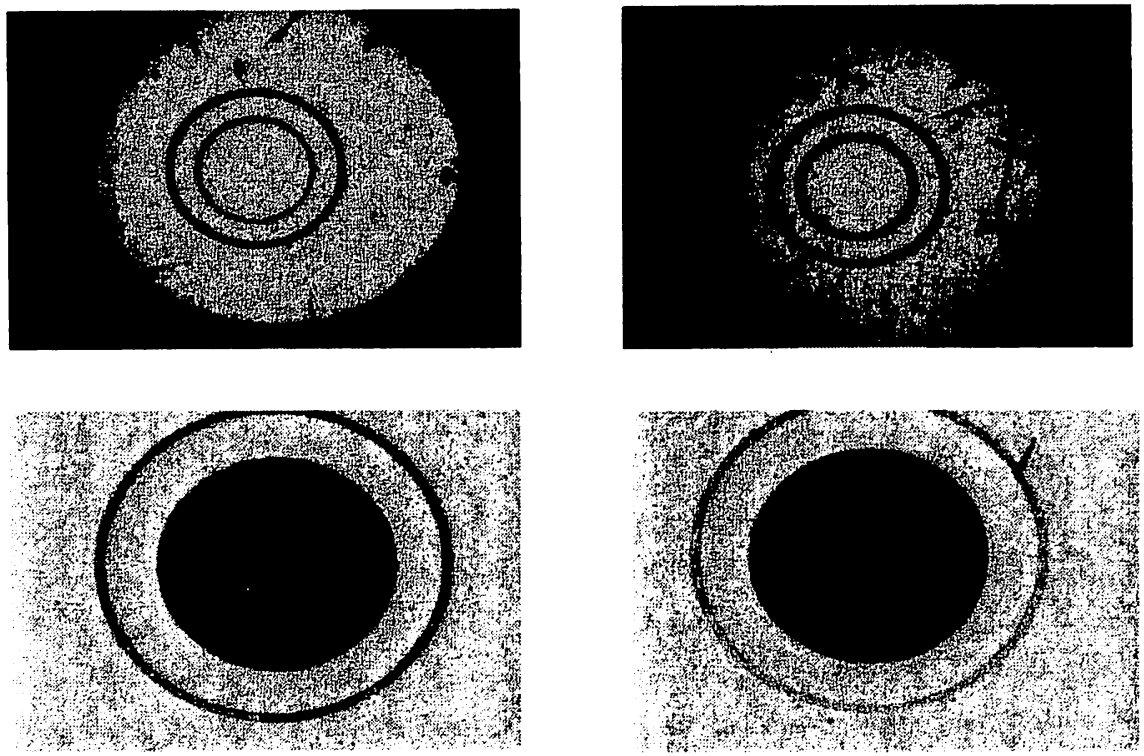

After $10.0 \mathrm{G}_{\mathrm{rms}}$ Testing

After $34.6 \mathrm{G}_{\mathrm{rms}}$ Testing

Figure 13: Endface images of FC connector showing damage during subsequent vibration testing.

Table 6: Insertion loss of FC cables before and after vibration testing.

\begin{tabular}{|c|c|c|c|}
\hline Cable Identification & $\begin{array}{c}\text { Insertion Loss } \\
\text { Pre-Vibration Testing }\end{array}$ & $\begin{array}{c}\text { Insertion Loss } \\
\text { Post-Vibration Testing }\end{array}$ & $\begin{array}{c}\text { Insertion Loss } \\
\text { Change (dB) }\end{array}$ \\
\hline FC-FC 400/440 SN-1 & 0.58 & 0.53 & -0.05 \\
\hline FC-FC 400/440 SN-2 & 0.62 & 0.29 & -0.33 \\
\hline FC-FC 400/440 SN - 3 & 0.52 & 0.58 & 0.06 \\
\hline FC-FC 400/440 SN - 4 & 0.72 & 0.39 & -0.33 \\
\hline
\end{tabular}


Table 6 shows the change in insertion loss of the FC cables before and after vibration testing. The maximum change was an improvement of $0.33 \mathrm{~dB}$. Again this is mainly.attributed to the test setup used to take these measurements.

\subsection{The SMA Connector}

The SMA connector has a fixed $3.16 \mathrm{~mm}$ diameter ferrule that is either ceramic or metal. There are two common varieties of SMA connectors, the SMA905 and SMA906. The SMA905 has the same diameter along the entire length of the ferrule, while the SMA906 drops to a smaller diameter near the connector endface. The metal ferrule SMA905 was used for all testing in this study. Figure 14 shows the SMA connector and adapter. There is no keying feature with this connector. The outer nut screws onto the adapter to hold the connector in place, so some type of secondary locking (usually epoxy or wire tie) is needed to ensure the connector does not loosen during harsh environments. The mating adapter for the SMA is a threaded barrel that has a smooth inner wall to align the fiber endfaces.

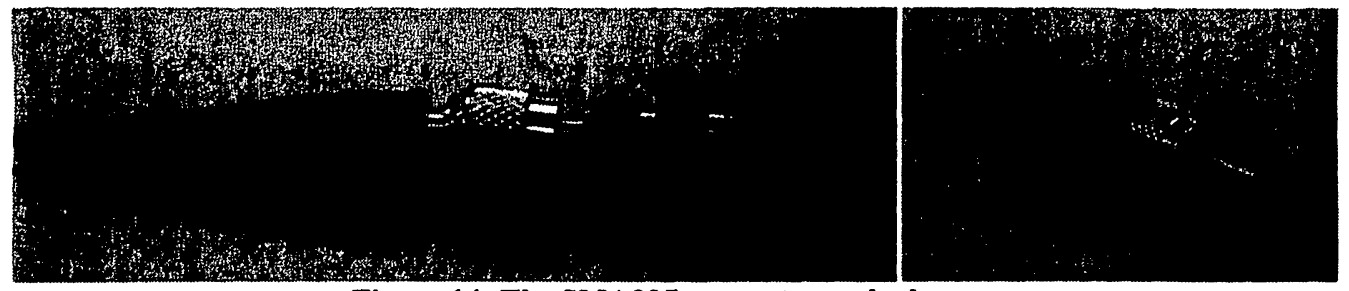

Figure 14: The SMA905 connector and adapter.

Insertion loss data taken during vibration testing for a 400/440 step index fiber is given in Figure 15. During this test the random vibration displacement was perpendicular to the long axis of the connector and adapter (parallel to the connector endface). The measurements exhibit more noise than in the AVIM and FC vibration testing because of the looser tolerances in the SMA adapter holding the alignment of the fiber endfaces. The effect becomes more noticeable in the smaller core fibers since the alignment mismatch of the fibers leads to larger changes in the insertion loss. Figure 16 shows data from vibration testing of a $100 / 140$ fiber in the same configuration. As can be seen from the graph, the fiber transmission showed a steady decrease (increasing insertion loss) throughout the $3 \mathrm{~min}$ vibration test. Not all of the smaller core fibers showed this effect, but it was not observed for any of the AVIM or FC vibration testing.

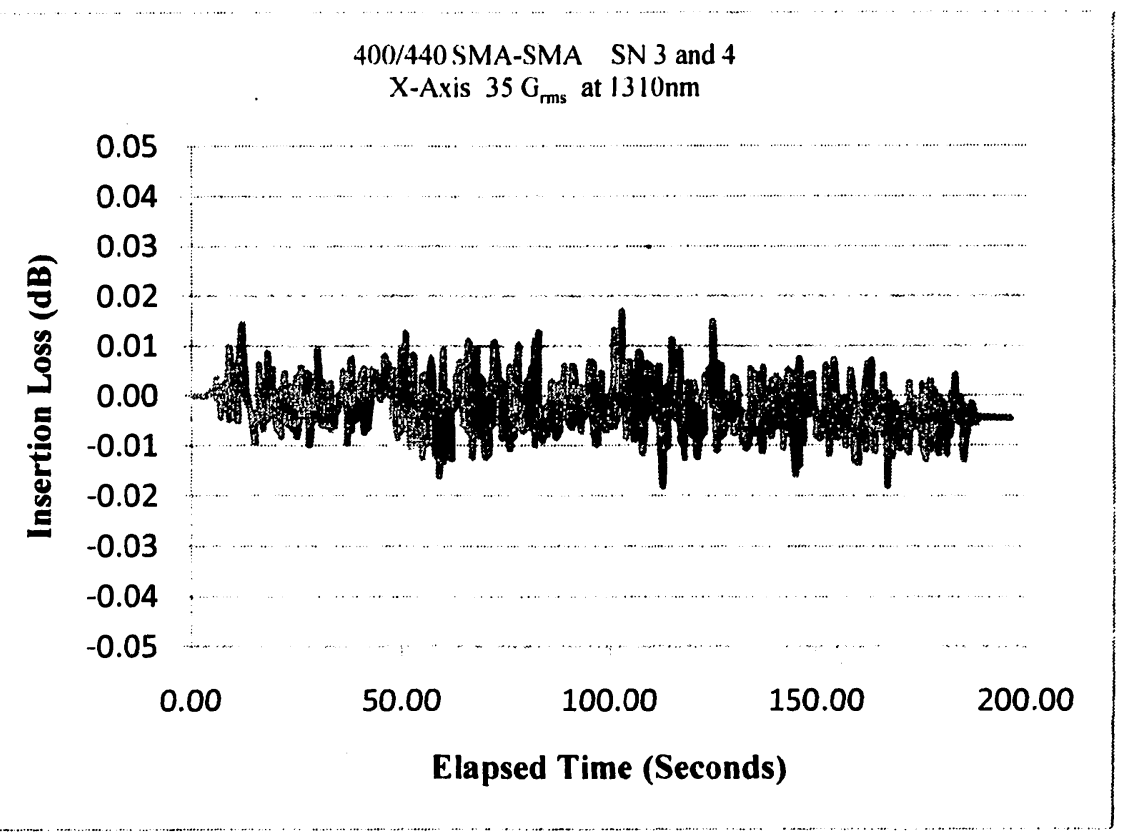

Figure 15: Insertion loss of $\mathbf{4 0 0 / 4 4 0}$ step index fiber in a SMA connector tested at 35 Grms parallel to the connector endface ( $X$ axis). 


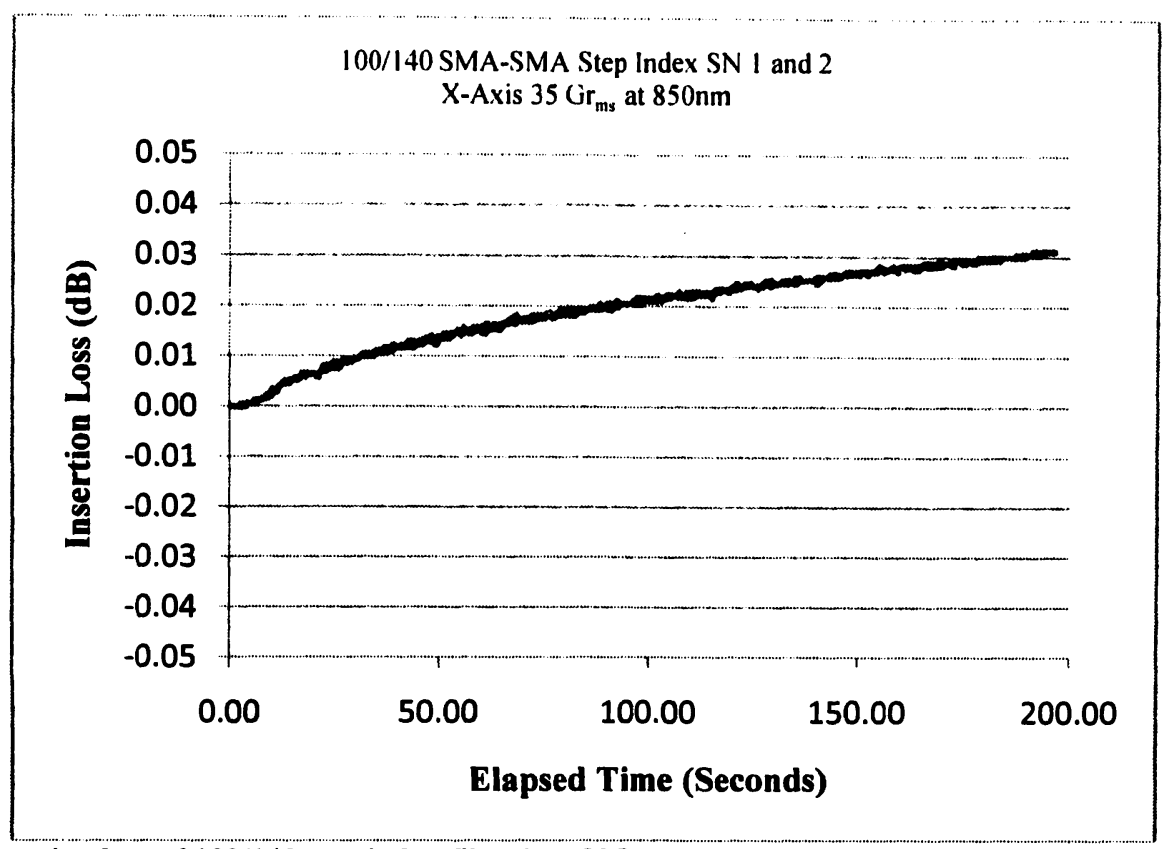

Figure 16: Insertion loss of 100/140 step index fiber in a SMA connector tested at 35 Grms parallel to the connector endface ( $X$ axis).
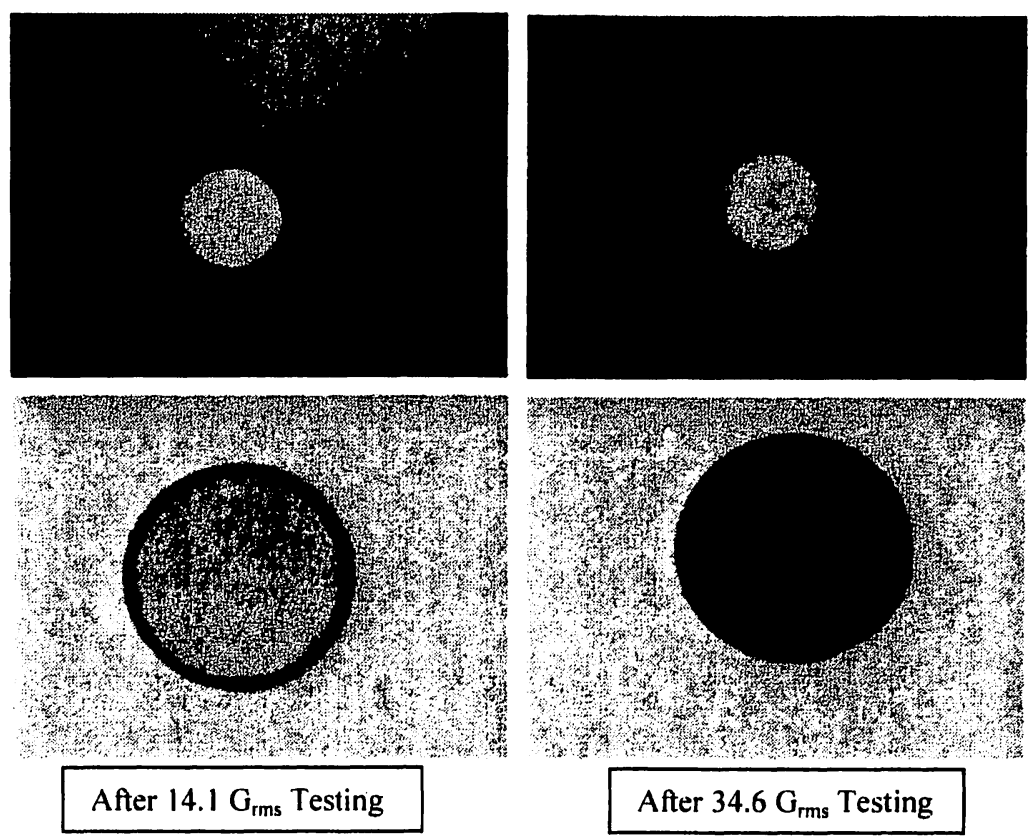

Figure 17: Endface images of $400 / 440$ fiber in a SMA connector showing damage during vibration testing.

Table 7: Insertion loss of SMA cables before and after vibration testing

\begin{tabular}{|l|c|c|c|}
\hline \multicolumn{1}{|c|}{ Cable Identification } & $\begin{array}{c}\text { Insertion Loss } \\
\text { Pre-Vibration Testing }\end{array}$ & $\begin{array}{c}\text { Insertion Loss } \\
\text { Post-Vibration Testing }\end{array}$ & $\begin{array}{c}\text { Insertion Loss } \\
\text { Change (dB) }\end{array}$ \\
\hline SMA-SMA 100/140 Step Index SN-1 & 0.419 & 0.528 & 0.109 \\
\hline SMA-SMA 100/140 Step Index SN-2 & 0.259 & 0.357 & 0.098 \\
\hline SMA-SMA 100/140 Graded Index SN-3 & 0.365 & 0.389 & 0.024 \\
\hline SMA-SMA 100/140 Graded Index SN-4 & 0.652 & 0.541 & -0.111 \\
\hline SMA-SMA 400/440 SN-3 & 0.322 & 0.343 & 0.021 \\
\hline SMA-SMA 400/440 SN - 4 & 0.433 & 0.289 & -0.144 \\
\hline
\end{tabular}


Figure 17 shows representative endface pictures of the SMA fibers taken following vibration testing at the specified levels. No damage was found on the glass fibers themselves, but the metal ferrule surrounding the fiber showed signs scratching and pitting. Due to the lack of a keying feature on the SMA connector, the ferrule can rotate inside of the adapter causing this type of circular damage pattern. Table 7 lists the insertion loss of the SMA cables before and after vibration testing. No permanent degradation of optical transmission for the SMA cables was found due to the vibration testing.

\subsection{The MIL-SPEC 38999 with 29504 Termini}

The MIL-SPEC-38999 connector is a multiferrule connector that holds 29504 termini, as shown in Figure 18. This connector is used in many space applications, such as the International Space Station, and military systems. Previous testing by our group on a 16 ferrule version of the 38999 using 29504/4 and /5 ferrule pins and sockets showed a change in insertion loss of less than $0.5 \mathrm{~dB}$ for vibration levels of 18.79 and $37.66 \mathrm{G}_{\mathrm{rms}}$. Some insertion loss changes larger than this were recorded, but they were attributed to variability in the SMA connectors used for connecting to the test instrumentation. One note from this testing was the amount of contamination found due to mating and demating of the connectors. It was suggested that a stringent cleaning method be used for these connectors to prevent particles from the connector getting on the fiber endfaces during mating and damaging the fibers. ${ }^{[5]}$

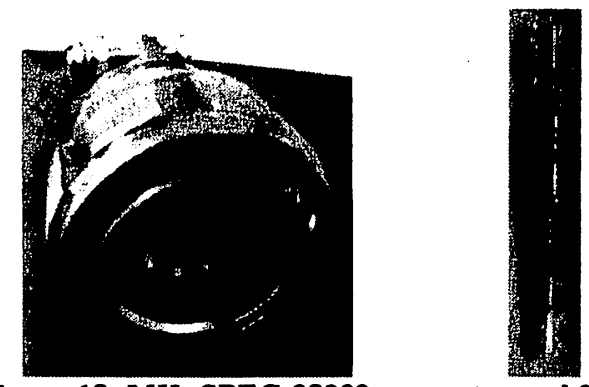

Figure 18: MIL-SPEC-38999 connector and 29504 termini.

\subsection{The MTP Connector}

The MTP is a multi-fiber fiber connector designed to allow mating of up to 24 fibers in a compact assembly. Most of our experience has been with the 12 fiber version of the connector. Typical fiber sizes used by our group with the MT ferrule are either $62.5 / 125$ or $100 / 140$, but other fiber types such as single mode 125 outer diameter fiber work without custom ferrules. The ferrule is a composite glass and epoxy matrix with two metal guide pins for alignment. The MT ferrule snaps into the MTP connector body for mating with each other. The plastic housings have indentations that snap together with the mating adapter and an outside spring loaded sleeve that prevents the "fingers" of the adapter from jumping out of the indentations. The outer sleeve must be retracted to disconnect the housing from the mating adapter.

The MTP were tested as part of an ongoing program and were therefore tested to the customer supplied vibration profile instead of the profiles given in the experimental design section of this paper. The vibration profile is given in Table 8. All 12 channels were monitored at $850 \mathrm{~nm}$ during the $3 \mathrm{~min} / \mathrm{axis}$ test.

Table 8: Vibration profile for MTP testing

\begin{tabular}{|l|l|l|}
\hline Frequency (Hz) & Level (Protoflight) & Units \\
\hline 20 & 0.03140 & $\mathrm{~g}^{\wedge} 2 / \mathrm{Hz}$ \\
\hline 70 & 0.48150 & $\mathrm{~g}^{\wedge} 2 / \mathrm{Hz}$ \\
\hline 140 & 0.48150 & $\mathrm{~g}^{\wedge} 2 / \mathrm{Hz}$ \\
\hline 150 & 0.25100 & $\mathrm{~g}^{\wedge} 2 / \mathrm{Hz}$ \\
\hline 300 & 0.25100 & $\mathrm{~g}^{\wedge} 2 / \mathrm{Hz}$ \\
\hline 400 & 0.10000 & $\mathrm{~g}^{\wedge} 2 / \mathrm{Hz}$ \\
\hline 600 & 0.10000 & $\mathrm{~g}^{\wedge} 2 / \mathrm{Hz}$ \\
\hline 2000 & 0.00900 & $\mathrm{~g}^{\wedge} 2 / \mathrm{IIz}$ \\
\hline Overall & 12.78 & Grms \\
\hline
\end{tabular}


The MTP connector with multimode fiber showed a change in insertion loss of less than $0.5 \mathrm{~dB}$ during testing with typical results much lower. Four fibers exhibited evidence of some movement during vibration with minor scratching/pitting of the fiber endfaces. Figure 19 shows the endface pictures following vibration testing for these connectors. These results are consistent with vibration testing performed by this group previously for other programs. ${ }^{[6]}$

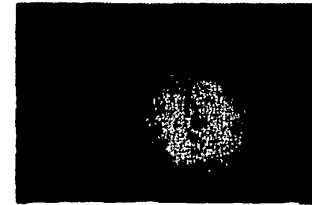

B1 MT Ch11

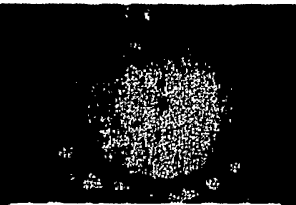

B5 MT Ch11

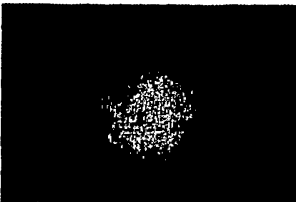

B1 MT Ch12

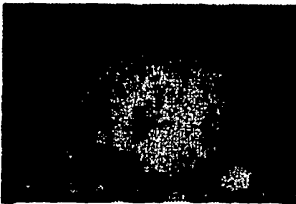

B5 MT Ch12

Figure 19: Fiber endfaces following vibration testing at $12.78 \mathrm{Grms}$.

Endface geometry will influence performance of the MTP connector in a mated pair configuration. Figure 20 shows endfaces taken on two different fiber optic cables that were terminated by an outside vendor and sent to GSFC for inspection. The desired geometry is for all of the fibers to be equal in height and slightly protruded from the composite ferrule as in the image of the left. However, if not tightly controlled and inspected, the fibers can be polished at uneven heights resulting in the geometry as on the right. The uneven fibers will be spring-loaded into the mating fibers and the forces will be carried by the couple of fibers protruding higher than the rest. This will likely result in performance fluctuations and fiber damage.
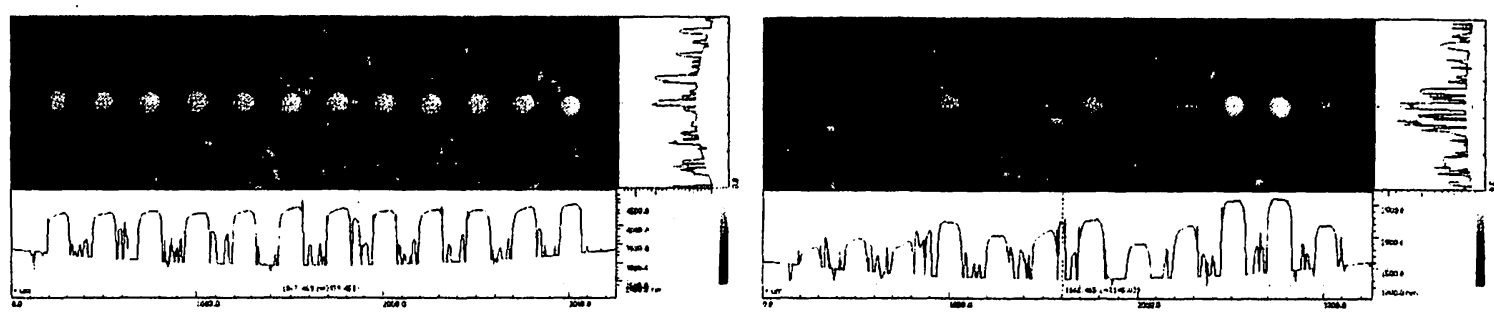

Figure 20: MTP fiber geometry on cables manufactured by an outside vendor and sent to GSFC for inspection. Uneven polishing of connector on right will result in uneven loading of fibers resulting in higher insertion loss fluctuations and possible damage.

\subsection{The ST Connector}

The ST connector has a $2.5 \mathrm{~mm}$ diameter ferrule that is ceramic, metal, or ceramic with a metal insert. The body of the connector is spring loaded against the outer "nut". A key on the connector provides alignment and prevents rotation of the ferrule inside the adapter. Two slots in the outer "nut" slide over small tabs on the adapter and are locked by twisting to engage the tabs into offset indentations in the slots. Figure 21 shows the ST connector and a mating adapter.

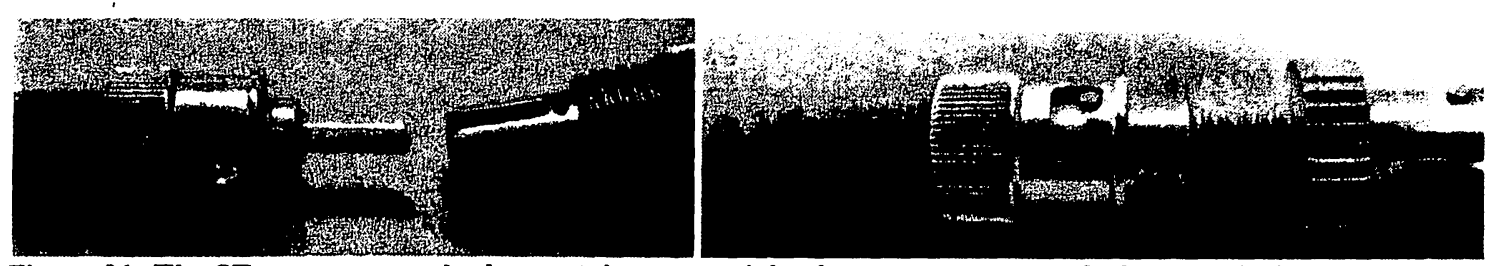

Figure 21: The ST connector and adapter (picture on right shows engagement of adapter tabs into connector slots.

ST connectors are commonly found on testing equipment. They provide a quick method of connecting fiber optic cables. However, they do not provide as high a level of mechanical ruggedness compared to other available fiber optic connectors for use in harsh environments. A small twist in the outer nut of the connector will disengage the locking mechanism causing the two mating connectors to spring apart from 
each other. Likewise, failure of the small metal tabs on the adapter will cause the connectors to spring apart also. For these reasons, the ST connector was not tested as part of this vibration study and would not be recommended for use in harsh environments.

\section{CONCLUSIONS}

Data are presented for vibration testing of AVIM, FC, and SMA fiber optic connectors up to $34.6 \mathrm{G}_{\mathrm{nns}}$. All connectors showed stable optical transmission with no damage to the fibers. In all cases, scratching and pitting of the metal ferrule outside the fiber was observed. The SMA connectors showed slightly higher fluctuations during testing, but this is expected due to the SMA adapter design. The SMA connectors also exhibited circular scratching of the ferrules due to a lack of a keying feature. Data was also given for vibration testing of a MIL-SPEC-38999 connector with 29504 termini and an MTP connector. Both of these connectors show insertion loss changes of $0.5 \mathrm{~dB}$ or less during vibration testing up to 37.6 and 12.78 $\mathrm{G}_{\mathrm{rms}}$ respectively. However, endface geometry must be controlled to prevent damage to the fibers when using these types of connectors.

In general, vibration does not significantly influence a properly designed fiber optic cable and connector for the types of environments tested, such as for space flight. System constraints like size, weight, locking features, etc. will influence which type of fiber connector is best suited for a particular application. Some of the desirable characteristics of a fiber connector, which will be mated to another fiber, to ensure stable operation during vibration include: a spring loaded ferrule, an alignment key to prevent rotation, a threaded outer nut to ensure stable engagement, and a properly designed adapter to hold alignment of the ferrules.

\section{ACKNOWLEDGMENTS}

The authors would like to thank the NASA Electronic Parts and Packaging Program (NEPP) for providing funding for this work. In addition, we would like to thank Kenneth Mautino and Tamas Heszler for machining of the vibration fixtures used during testing.

\section{REFERENCES}

[1] Melanie N. Ott, "Validation of Commercial Fiber Optic Components for Aerospace Environments" SPIE Conference on Smart Structures and Materials, Smart Sensor Technology and Measurement Systems, Vol. 5758, March 2005.

[2] Lisa McMurray, "Tests and results of active alignment fiber optic connectors for space usage," SPIE Conference on Photonics for Space Environments IV, Vol. 2811, 1996.

[3] Melanie N. Ott, Dr. Xiaodan "Linda" Jin, Richard Chuska, Patricia Friedberg, Mary Malenab, and Adam Matzuseski, "Space Flight Requirements for Fiber Optic Components; Qualification Testing and Lessons Learned," International Society for Optical Engineering, SPIE Europe Conference on Reliability of Optical Fiber Components, Devices, Systems and Networks III, Vol. 6193, April 2006.

[4] General Environmental Verification Standard (GEVS), NASA Goddard Space Flight Center, GSFCSTD-7000 (2005).

[5] Jeannette Plante. "Evaluation report for the Amphenol-Bendix 453 miniature circular connector with MIL-T-29504 optical termini in a vibration environment," available at http photonics. gsfc.nasa.gov or http. misspiggy.gsfc.nasa.goviphotonics.

[0] Xiaodan "Linda" Jin, Melanie N. Ott, Frank V. LaRocca, Ronald M. Baker, Bianca E.N. Keeler, Patricia R. Friedberg, Richard F. Chuska, Mary C. Malenab, and Shawn L. Macmurphy. "Space Flight Qualification on a Multi-Fiber Ribbon Cable and Array Connector Assembly," International Society for Optical Engineering. SPIE Optics and Photonics Conference on Photonics for Space Environments XI, Photonics Technologies for Radiation Environınents II, Vol. 6308, August 2006. 